\title{
Frank Lestringant, Une sainte horreur ou Le voyage en Eucharistie (XVI ${ }^{\mathrm{e}}-\mathrm{XVIII}{ }^{\mathrm{e}}$ siècles)
}

\section{Dario Cecchetti}

\section{OpenEdition \\ Journals}

\section{Edizione digitale}

URL: http://journals.openedition.org/studifrancesi/3695

DOI: 10.4000/studifrancesi.3695

ISSN: 2421-5856

\section{Editore}

Rosenberg \& Sellier

\section{Edizione cartacea}

Data di pubblicazione: 1 décembre 2012

Paginazione: 555

ISSN: 0039-2944

\section{Notizia bibliografica digitale}

Dario Cecchetti, «Frank Lestringant, Une sainte horreur ou Le voyage en Eucharistie (xvi ${ }^{e}-x v I{ }^{e}$ siècles)», Studi Francesi [Online], 168 (LVI | III) | 2012, online dal 30 novembre 2015, consultato il 08 mars 2021. URL: http://journals.openedition.org/studifrancesi/3695 ; DOI: https://doi.org/10.4000/studifrancesi. 3695

Questo documento è stato generato automaticamente il 8 mars 2021.

\section{(c)}

Studi Francesi è distribuita con Licenza Creative Commons Attribuzione - Non commerciale - Non opere derivate 4.0 Internazionale. 
Frank Lestringant, Une sainte horreur ou Le voyage en Eucharistie (XVI ${ }^{\mathrm{e}}-\mathrm{XVIII}{ }^{\mathrm{e}}$ siècles)

Dario Cecchetti 


\section{NOTIZIA}

FRANK LESTRINGANT, Une sainte horreur ou Le voyage en Eucharistie (XVI $-\mathrm{XVIII}{ }^{e}$ siècles), préface de Pierre CHAUNU, Genève, Droz, 2012, 2e édition revue et corrigée («Titre courant», 46), pp. 421.

1 Viene riproposto, in edizione economicamente accessibile, l'importante libro di F. Lestringant, ormai esaurito, sull'impatto della dottrina eucaristica non soltanto sugli scontri teologici fra cattolici e calvinisti, ma anche, a livelli diversissimi, sull'immaginario letterario e sui risvolti culturali in senso antropologico che assume in culture diverse il tema del pasto antropofagico (non dimentichiamo che fin dalle origini della polemica anticristiana - si rileggano l'Octavius di Minucio Felice e il Contro Celso di Origene - emergeva l'accusa di antropofagia per una ricezione travisata del discorso eucaristico). Interessato particolarmente al Cinquecento, l'A. costruisce un quadro non tanto delle discussioni e degli sviluppi dottrinali, quanto delle reazioni sul piano della storia delle mentalità, scandendo alcune tappe - l'affaire des Placards, le guerre civili e le persecuzioni religiose (da parte di entrambe le confessioni), le considerazioni sulle pratiche cannibaliche nel Nuovo Mondo ad opera dei relatori di viaggio in Brasile o di Montaigne - tappe che hanno una rilevanza per lo studio anche dell'immaginario letterario (emergono riferimenti a testi come Hamlet o Les Tragiques). La scansione, essenzialmente cinquecentesca, viene prolungata al Sei e Settecento, con incursioni che vanno da Cyrano a Port-Royal, da Saint-Evremond a Swift. Rispetto alla prima edizione, questa ristampa aggiornata è arricchita di nuova documentazione nel capitolo sul Théâtre des cruautés di Verstegan e di approfondimenti nel capitolo su Montaigne. 